\title{
Clinical utility of cardiovascular magnetic resonance in patients with cardiac rhythm management devices
}

\author{
Nikhil Jariwala*, Lara Bakhos, Jeffrey R Winterfield, Mark Rabbat, Mushabbar A Syed \\ From 19th Annual SCMR Scientific Sessions \\ Los Angeles, CA, USA. 27-30 January 2016
}

\section{Background}

Selected patients with cardiac rhythm management devices (CRMD) can safely undergo cardiovascular magnetic resonance (CMR). However, susceptibility artifacts from CRMD generator and leads can affect image quality, limiting the information provided by CMR. We sought to evaluate whether CMR of CRMD patients can provide clinically useful information that includes answering the clinical question, providing new findings, new diagnoses, or change in clinical management.

\section{Methods}

We studied 89 patients with CRMD who were evaluated for CMR from November 2012 through June 2015. Eighteen patients were excluded for various MRI contraindications. The remaining 71 patients completed the scan without complications. All CRMD were interrogated prior to the scan. For pacemaker dependent patients, asynchronous pacing was used during CMR. Device therapies were turned off for implantable cardioverter defibrillator (ICD) patients. CMR images were acquired on a 1.5 Tesla (Siemens Aera) scanner using standard sequences including single shot black blood imaging, cine with SSFP or FLASH, first pass perfusion, and late gadolinium enhancement (LGE). During the scan, patients were monitored with continuous vitals, ECG, oximetry, and voice contact. All CRMD were re-interrogated after the scan and original settings were restored. Images were evaluated using $\mathrm{CMR}^{42}$ (Circle Cardiovascular Imaging) software.

\section{Results}

Baseline characteristics are listed in Table 1. ICD was present in $58(81.7 \%)$ and pacemaker in $13(18.3 \%)$

Cardiology, Loyola University, Chicago, IL, USA patients. Common CMR indications included evaluation for ventricular arrhythmia substrate $(\mathrm{n}=61)$, hypertrophic cardiomyopathy $(\mathrm{HCM})(\mathrm{n}=6)$, and cardiac sarcoidosis $(n=4)$. Device artifact affected complete evaluation of myocardial segments in 17 patients (23.9\%) on cine imaging and in 50 patients $(70.4 \%)$ on LGE. CMR findings are summarized in Table 2. The most common findings were non-ischemic scar $(n=24)$, ischemic scar $(n=17)$, and combined scar $(n=6)$, which helped guide ventricular arrhythmia ablation. Additionally, a new diagnosis or finding was made in 14 patients (19.7\%), which included cardiac sarcoidosis $(\mathrm{n}=3)$ and arrhythmogenic right ventricular cardiomyopathy $(\mathrm{n}=2)$. In $3 \mathrm{HCM}$ patients, CMR findings guided the decision for alcohol septal ablation vs. surgical resection. Overall, the clinical question was answered in 66 patients (92.9\%).

\section{Conclusions}

Our results show that in carefully screened CRMD patients, CMR is safe, can answer the clinical question in

\section{Table 1 Baseline Clinical Characteristics}

\begin{tabular}{cc} 
Age (years) & $59.38( \pm 12.95)$ \\
Male & $59(83.0 \%)$ \\
Body mass index $(\mathrm{kg} / \mathrm{m} 2)$ & $29.54( \pm 6.31)$ \\
Body surface area $(\mathrm{m} 2)$ & $2.09( \pm 0.22)$ \\
Coronary artery disease & $25(35.7 \%)$ \\
Diabetes mellitus & $9(12.9 \%)$ \\
Hypertension & $40(57.0 \%)$ \\
Hyperlipidemia & $37(52.9 \%)$ \\
Ischemic cardiomyopathy & $16(22.9 \%)$ \\
Non-ischemic cardiomyopathy & $24(34.3 \%)$ \\
Mixed cardiomyopathy & $6(8.6 \%)$ \\
Previous ventricular arrhythmia ablation & $24(34.3 \%)$ \\
\hline
\end{tabular}


Table 2 CMR Findings

\begin{tabular}{cc}
\hline Non-ischemic scar & $24(33.8 \%)$ \\
Ischemic scar & $17(23.9 \%)$ \\
Combined ischemic and non-ischemic scar & $6(8.5 \%)$ \\
Hypertrophic cardiomyopathy & $4(5.6 \%)$ \\
Cardiac sarcoidosis & $3(4.2 \%)$ \\
Arrhythmogenic right ventricular cardiomyopathy (ARVC) & $3(4.2 \%)$ \\
Left ventricular involvement of ARVC & $2(2.8 \%)$ \\
Rejected cardiac sarcoidosis & $1(1.4 \%)$ \\
Rejected ARVC & $1(1.4 \%)$ \\
Accessory pulmonary vein & $1(1.4 \%)$ \\
Apical thrombus & $1(1.4 \%)$ \\
Pericardial lipomatosis & $1(1.4 \%)$ \\
Right ventricular pseudoaneurysm & $1(1.4 \%)$ \\
Severe aortic stenosis & $1(1.4 \%)$ \\
Subaortic membrane & $1(1.4 \%)$ \\
\hline
\end{tabular}

vast majority of patients, and can provide new information to guide clinical management.

Published: 27 January 2016

doi:10.1186/1532-429X-18-S1-0124

Cite this article as: Jariwala et al:: Clinical utility of cardiovascular magnetic resonance in patients with cardiac rhythm management devices. Journal of Cardiovascular Magnetic Resonance 2016 18(Suppl 1):0124.

\section{Submit your next manuscript to BioMed Central} and take full advantage of:

- Convenient online submission

- Thorough peer review

- No space constraints or color figure charges

- Immediate publication on acceptance

- Inclusion in PubMed, CAS, Scopus and Google Scholar

- Research which is freely available for redistribution

Submit your manuscript at www.biomedcentral.com/submit
C BioMed Central 